\title{
Death of a Salesman elementos da tragédia clássica no drama moderno de Arthur Miller
}

\author{
Alyne Ferreira de Araújo ${ }^{1}$ \\ Francisco Edson de Freitas Lopes \\ Daise Lilian Fonseca Dias ${ }^{2}$
}

Resumo: O objetivo deste trabalho é analisar, sob a perspectiva aristotélica, elementos da tragédia clássica em Death of a salesman [A morte do caixeiro viajante], escrita em 1949 por Arthur Miller (1915 - 2005), um dos mais influentes dramaturgos americanos. A peça em questão denuncia e desmistifica a ideia do Sonho Americano através da história de Willy Loman, um caixeiro viajante que possui uma obsessiva fixação pelos ideais de progresso, tanto financeiro como familiar, o que o leva a uma busca idealizada por uma vida perfeita ao lado de sua família. No entanto, as exigências da sociedade capitalista e sua busca por reconhecimento e sucesso acabam lhe proporcionando um fim trágico. Na época em que o texto de Miller foi escrito, a sociedade americana estava em um momento pós-guerra, e o autor, através de sua obra, traz para o centro dos debates as relações do indivíduo em conflito com o meio social. Além disso, embora sua peça não seja considerada uma tragédia clássica e sim um drama moderno, em Death of a salesman, estão presentes elementos característicos da tragédia clássica. Sendo assim, é necessário observar-se como aquela tragédia, proveniente dos gregos, transformou-se no drama moderno; partindo deste ponto, serão analisados tais elementos dentro do texto de Miller.

Palavras-chave: Literatura. Tragédia. Drama Moderno.

\section{DEATH OF A SALESMAN: ELEMENTS OF CLASSICAL TRAGEDY IN ARTHUR MILLER'S MODERN DRAMA}

\begin{abstract}
The objective of this paper is to analyze elements of classical tragedy, from the Aristotelian perspective, in Death of a salesman, written in 1949 by Arthur Miller (1915-2005), one of the most influential American dramatists. The play denounces and demystifies the idea of the American Dream through the story of Willy Loman, a salesman who has an obsessive fixation for ideals of progress, either financial or familiar, but that leads him to an idealized search for a perfect life. However, the demands of the capitalist society in which he lives and his search for success and recognition by his peers and family members take him to a tragic ending. At the time Miller's text was written, the American society was living a post-war period, and the writer, through his work, brings to the center of the debate the individual's relations with his conflicting environment. Besides, although his play is not considered a classical tragedy but a modern drama, Death of a salesman has common elements of the classical tragedy. Thus, this paper will discuss how that tragedy, originally written and performed by the Greeks, was transformed in a modern drama; having this in mind, such elements will be analyzed in Miller's text.
\end{abstract}

Keywords: Literature. Tragedy. Modern Drama.

\section{Introdução}

\footnotetext{
${ }^{1}$ Alyne e Edson são alunos do Curso de Graduação em Letras Língua Inglesa do Centro de Formação de Professores da UFCG. E-mail: alynef_araujo@hotmail.com; edson.freitas9@hotmail.com
2 Daise Lilian é graduada em Letras Língua Inglesa (UFRN), mestre em Literaturas de Língua Inglesa (UFPB).(3) doutora em Literatura e Cultura (UFPB) e professora da área de Língua Inglesa do Curso de Letras Língua Inglesa do Centro de Formação de Professores da UFCG. E-mail: daiselilian@ @otmail.com.com
} 
Este artigo tem como objetivo analisar elementos característicos da tragédia na peça Death of a salesman [A morte do caixeiro viajante], escrita em 1949 por Arthur Miller (1915 - 2005), um importante autor americano, considerado por muitos estudiosos como um dos melhores dramaturgos do século XX, à luz da Poética (1985), de Aristóteles, dentre outros. Miller sofreu grande influência do dramaturgo norueguês Henrik Ibsen (1828 - 1906), uma vez que suas obras tratam de questões sociais, morais e políticas, de forma revolucionária. O estilo literário do autor é composto de obras centradas em aspectos sociais, envolvendo temas como dramas familiares, relacionamentos conturbados entre pai e filhos, a relação do indivíduo com a sociedade, crescimento pessoal e responsabilidade familiar. Além disso, segundo Christopher Bigsby, em seu livro Modern American Drama (2000), os personagens retratados por Miller parecem estar sempre se defendendo de acusações, tentando tomar o controle de suas vidas e escapar das consequências de seus atos, o que implica em transferência de culpa ou em suicídio.

Em Death of a salesman (1972), Arthur Miller discute a clássica história do fim trágico do herói através de Willy Loman, um vendedor de sessenta e poucos anos que, ao lado de sua esposa, Linda, e seus filhos Biff e Happy, vê sua vida profissional e familiar ser desestruturada em virtude de sua ilusão e busca exagerada por riqueza e sucesso financeiro. Mesmo fracassado, Willy representa o típico herói do Sonho Americano. Em sua busca por atingir esse Sonho que lhe é inalcançável, ele transfere para seu filho mais velho Biff o ideal de sucesso que almejava alcançar e não conseguiu. Contudo, as esperanças que Willy deposita no filho são frustradas, uma vez que ele próprio desconstruiu a imagem idealizada de pai que Biff tinha no passado, quando o garoto o flagra com uma prostituta. A partir de então, Willy passa a ter alucinações sobre momentos de seu passado, e também algumas conversas imaginárias com seu irmão Ben, o qual é um símbolo do progresso que Willy tanto almeja.

Nesse contexto, é importante destacar que, na época em que a referida peça foi escrita, a sociedade americana estava em um momento pós-guerra. $\mathrm{O}$ país estava vivendo um período de crise que ficou conhecido como a Grande Depressão, no entanto, em meio à crise e ao fracasso americano, muitos continuavam alienadamente presos aos ideais fantasiosos do "American way of life". Dessa forma, Arthur Miller, através de sua obra, faz críticas de caráter social aos valores ideológicos do modo de vida americano, devido ao fato de que sua peça retrata a real situação americana pós-guerra, contestando assim o clima de sonho e fantasia existente na época - e tão comum desde a colonização dos Estados Unidos. 


\section{0 fracasso do Sonho Americano}

O drama de Willy Loman é o de um homem que já está no fim de sua carreira como vendedor, e que não aceita ter fracassado como pai (perdeu confiança e o amor dos filhos quando traiu sua mulher), como marido (nunca conseguiu ter sucesso financeiro, pesa-lhe também o preço da traição), como funcionário (suas vendas caem profundamente a cada ano, ao ponto de trabalhar por comissão). Willy perde espaço familiar (seus filhos não têm mais o mesmo relacionamento - muito menos o amor e o respeito - de antes para com ele) e financeiro (porque seu trabalho não tem mais a importância de antes, visto que ele não acompanhou as novas técnicas e modernizações do mercado).

Dessa forma, devido à infelicidade por sua real situação, Willy prefere sonhar e relembrar acontecimentos passados, pois tudo mudou em sua vida e ele se satisfaz através de lembranças e fantasias. Elas ocorrem na peça por meio de elementos épicos como monólogos imaginários, flashbacks e pela projeção da sua própria consciência nas cenas com Ben. Tais recursos do drama moderno de Miller são introduzidos de maneira a intensificar o conflito presente, permitindo ao público tomar consciência do processo conflituoso na vida da família Loman.

A esposa de Willy, Linda, é retratada como uma mulher abnegada e submissa, dedicada somente ao marido, aos filhos e à casa. Conhecedora dos problemas do marido, ela tenta protegê-lo da tenebrosa realidade. O filho mais novo do casal, Happy, é bem sucedido, porém não é feliz como seu nome ironicamente sugere, devido ao fato de que ele não tem a atenção devida do pai e procura sempre imitar o irmão, Biff, para chamar a atenção de Willy. Biff, pelo contrário, é o filho favorito dos pais, já que no passado ele obteve sucesso, sendo o campeão do time de futebol da escola; era nele que Willy depositava todas as esperanças de glória e sucesso. No entanto, Biff tornou-se preguiçoso e vagabundo, após ter a imagem do pai-herói irremediavelmente desconstruída ao descobrir a infidelidade conjugal paterna. Arruinado com tal descoberta, ele desiste dos próprios sonhos e atribui seus problemas e fracassos ao choque de realidade que sofreu através do erro do pai.

Death of a salesman (1972) aborda temas como o fracasso do Sonho Americano, o qual predomina durante toda a história, levando o protagonista a cometer erros que o conduzem ao próprio declínio. O Sonho Americano está profundamente relacionado às utopias de colonização dos Estados Unidos, que seriam, por exemplo, a divulgação de que aquela nova nação seria uma terra de igualdade e oportunidade para todos, ou seja, um lugar 
onde todos poderiam viver livre das pressões de um sistema político monárquico, por exemplo, e enriquecer com facilidade. Na prática isso não funcionava como os planfletos de propaganda do novo país sugeria, à época da colonização, contudo, como aqueles ideais foram atingidos por muitos, eles ficaram cristalizados no imaginário da população local e pessoas de outros países que, inspiradas por eles, imigraram para aquele novo mundo.

No caso de Willy, tanto ele quanto seus filhos teem uma vida de fracasso financeiro, enquanto seus conhecidos só progridem e atingem o desejado Sonho Americano. Ele, como patriarca, não suporta ter seus esforços reduzidos a nada, o que o leva a optar por fugir da realidade, fantasiando perspectivas irreais para o futuro e para o presente, de modo que passa a oscilar entre a sanidade e a insanidade. Seu fim é cometer suicídio, para que Biff - o filho favorito da família - tenha a possibilidade de, com o dinheiro do seguro de vida do falecido pai, abrir uma empresa para si e, então, realizar o Sonho Americano de sucesso financeiro. O trecho final da peça mostra apenas a realização de um dos sonhos do protagonista: a casa onde vivia com a família, a qual ele pagou durante toda a sua vida de casado, agora estava quitada.

Outro tema abordado é o abandono. Esta questão está ilustrada tanto na traição de Willy como também no fato de que, a sua infância, ele e sua família foram abandonados pelo pai (tudo indica que isso se deu pela incapacidade do patriarca de fazer seu papel de provedor da família, no auge da Grande Depressão americana - dificuldades financeiras estão no cerne das discussões das obras de Miller). A ausência da figura paterna desenvolve uma carência excessiva de atenção e reconhecimento por parte de Willy - conflitos entre pai e filho são a principal característica da temática do autor. No entanto, isso promove no caixeiro viajante um complexo de superioridade em vez de inferioridade.

\section{Da tragédia clássica ao drama moderno}

Em Introdução à Dramaturgia (1988), Renata Pallottini diz que a arte teatral tem sido estudada com o objetivo de analisar os elementos característicos que constituem a essência da obra dramática. Séculos atrás, Aristóteles, em sua Poética (1985), estabelece elementos da ação dramática que definem a tragicidade ou a comicidade de uma peça. Quanto a isso, Death of a salesman (1972) é vista de maneira controversa na dramaturgia moderna, pois alguns escritores consideram o enredo da peça como sendo uma tragédia, enquanto outros a classificam apenas como pathos (B LOOM, 1987), sobre o qual, em seu Dicionário de Teatro, Patrice Pavis afirma ser a "qualidade da obra teatral que provoca emoção no espectador" (PAVIS, 1999, p. 280). Ela seria um pathos porque uma tragédia não poderia ser 
evitada, mas a de Willy poderia ter sido, bastava-lhe abrir mão do orgulho exagerado que nutria em relação à própria capacidade de vencer e aceitar o novo emprego que lhe é oferecido, sobretudo porque no drama moderno, o seu destino trágico não é traçado pelos deuses de modo irrevogável, como nas tragédias clássicas.

Em relação ao conceito de pathos, o autor ainda se reporta a Aristóteles:

[...] o pathos é a parte da tragédia que, em função da morte ou dos acontecimentos trágicos da personagem, provoca sentimentos de piedade e de terror [...] (apud PAVIS, 1999, p. 280).

Sendo assim, o que se define por pathos está, portanto, ligado à katharsis (catarse) que provoca temor e pena e ao acontecimento doloroso, a catástrofe. Ora, segundo Aristóteles (1985), a catarse é o efeito que se espera da tragédia, ou seja, a purificação dos sentimentos de piedade e terror suscitados pela trama dos fatos e pela identificação com a personagem principal da ação trágica. Já a catástrofe, é a ação perniciosa e dolorosa, como também são as mortes em cena, as dores veementes, os ferimentos e mais casos semelhantes. Assim, o teatro, em particular a tragédia, recorre ao pathos quando convida o público a se identificar com uma situação ou causa, por meio da katharsis, o que causará o efeito de purificação dos sentimentos de piedade e terror adquiridos pelo público.

Com relação à tragédia, é recorrente entre estudiosos da área, tais como Williams (2002) e Cunha (1976), a concepção de que, atualmente, não há a possibilidade de existirem tragédias semelhantes às gregas, visto que, as diferenças entre as civilizações e as transformações ocorridas ao longo do tempo nas sociedades e o desenvolvimento do teatro são fatores impeditivos. Contudo, a peça de Miller apresenta elementos característicos do trágico (visto ser este um elemento/princípio universal anterior à criação das tragédias enquanto gênero literário, assumindo assim algumas das características da tragédia clássica, descritas por Aristóteles em sua Poética. Para que melhor seja compreendida esta questão, é necessário observar-se o conceito de drama, aspectos da dramaturgia, e também como a tragédia clássica transformou-se no drama moderno, considerando-se, assim, as mudanças pelas quais passou a tragédia.

De acordo com Chris Baldick, em seu Oxford concise dictionary of literary terms (1996), drama (do grego drama = ação) define-se pela performance de ações e falas de personagens fictícios ou históricos para o entretenimento de um público, seja em um palco ou por meio de uma transmissão. Na antiguidade clássica, o drama era entendido por døis tip@s de representação: a tragédia (ações dirigidas por meio de uma fatalidade e com um desfecho

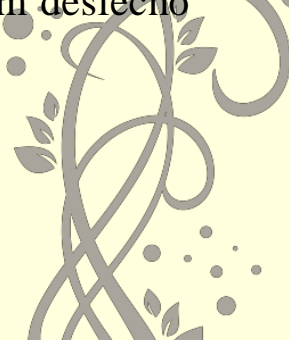


funesto) e a comédia (ações jocosas; fatos da vida social com um desfecho feliz). Entretanto, a partir do século XIX até os dias atuais, os dois elementos se unem de maneira a concentrarem os temas da vida social por meio do trágico e, muitas vezes, do cômico.

É preciso considerar que o teatro, especificamente a tragédia clássica, tem sua origem nos cultos e rituais a Dionísio (deus do vinho, da luxúria e do prazer), o qual possuía uma composição e uma estrutura própria de representação. Porém, com a passagem da Idade Antiga para as idades posteriores, e com o avanço das sociedades ao longo da história, surgiram novas formas de teatro e de dramaturgia, de modo que, principalmente a tragédia, sofreu várias transformações como, por exemplo, a mudança de público, de linguagem e o fato de ter se tornado mais doméstica, na busca pela realidade social de cada época. Sendo assim, a tragédia ganha novos aspectos sociais, novas temáticas, o que resultou no surgimento do drama moderno (LUNA, 2005).

De acordo com Raymond Williams, em Tragédia Moderna (2002), a passagem da tragédia clássica para o drama moderno promoveu uma mudança em relação ao seu contexto, de maneira que ela passou de um universo mítico e religioso para um universo mais secular. Segundo Peter Szondi, em Teoria do Drama Moderno (2001), o drama moderno surge no Renascimento, quando a partir da supressão do prólogo, do coro e do epílogo, a forma dramática passou a concentrar-se na representação dos personagens por meio dos diálogos. Além disso, o personagem trágico na modernidade passa a ser a representação do homem comum e da sociedade em que ele vive, o qual tem o controle próprio de suas ações, podendo evitar sua tragédia.

Tais mudanças representam - o que, de fato, já ocorria nos tempos de Eurípedes com sua Medéia - uma ruptura com os padrões elencados por Aristóteles (1985) para uma tragédia ideal. A título de ilustração, tem-se a definição aristotélica de tragédia como a imitação ou representação de uma ação elevada e completa, executada por personagens que representam os homens melhores do que são a fim de despertar piedade e terror e obter a catarse, ou seja, a purificação dessas emoções. Nesse sentido, com relação à tragédia e sua estrutura, é possível notar que Death of a salesman (1949) apresenta alguns dos elementos postulados por Aristóteles, característicos da tragédia clássica, caracterizando-se, portanto, como uma tragédia, embora com transformações naturais de um texto dramático do século XX, sendo, portanto, uma tragédia moderna. Assim, torna-se necessário analisar a presença desses elementos característicos da tragédia no drama moderno de Arthur Miller. 


\section{Tragédia ou drama moderno?}

Para Aristóteles (1985), o primeiro, e mais importante, elemento constituinte da tragédia é a fábula (o enredo), sobre o qual ele afirma ser "a alma da tragédia", pois é a partir do enredo que todo o conflito será determinado, devendo esse possuir princípio, meio e fim. Desse modo, pode-se dizer que o drama de Arthur Miller segue os princípios aristotélicos a respeito do enredo, visto que a peça possui um princípio (o herói se torna um vendedor bem sucedido com a família), um meio (o início dos problemas na vida do herói em relação à sua profissão) e um fim trágico (momento em que o herói morre). Na peça de Miller tudo está conectado, de maneira que, todas as cenas são necessárias para a totalidade da obra.

Ainda com relação ao enredo, para Aristóteles, o melhor enredo é o complexo, no qual algo positivo torna-se negativo, desenvolvendo-se do reconhecimento (do grego anagnorisis) para a peripécia (do grego peripéteia. Aristóteles afirma que o reconhecimento é "a mudança do desconhecimento ao conhecimento, ou à amizade, ou ao ódio, das pessoas marcadas para a ventura ou desdita [...]" (ARISTÓTELES, 1985, p. 30). Em outras palavras, a verdade se constitui como um choque para o personagem, provocando uma mudança da ignorância para a consciência. Em Death of a salesman (1972, pgs. 93 e 94, respectivamente), o reconhecimento acontece quando Willy, enquanto conversa com seu sobrinho Bernard, toma consciência de que o verdadeiro motivo da revolta de Biff contra ele foi o fato de que, seu filho o viu traindo sua esposa Linda com uma mulher em Boston:

BERNARD: He wasn't beaten by it at all. But then, Willy, he disappeared from the block for almost a month. And I got the idea that he'd gone up to New England to see you. Did he have a talk with you then?

WILLY: Yeah, he came to Boston. What about it?

BERNARD: Well, just that when he came back - I'll never forget this, it always mystifies me. [...] And he came back after that month and took his sneakers $[\ldots]$. He took them down in the cellar, and burned them up in the furnace. [...] I've often thought of how strange it was that I knew he'd given up his life. What happened in Boston, Willy? (MILLER, 1972, p. 94). ${ }^{3}$

\footnotetext{
${ }^{1}$ BERNARD: Ele não foi vencido por ela absolutamente. Mas em seguida, Willy, ele desapareceu da quadra por quase um mês. E eu tive a ideia de que ele tinha ido até a Nova Inglaterra para vê-lo. Ele teve uma conversa com você, então?

WILLY: Sim, ele foi para Boston. E daí?

BERNARD: Bem, quando ele voltou - Eu nunca esquecerei isso, isso sempre me intrigou. [...] Ele voltou depois de um mês e pegou seus tênis [...]. E então os jogou no porão e os queimou na fornalha. [...] Eu sempre pensei como era estranho o fato de saber que ele tinha desistido de sua vida. O que aconteceu em Boston, Willy? (MILLER, 1949, p. 93 e 94, tradução nossa).
} 
No momento da conversa com Bernard, Willy relembra o dia em que Biff foi até o hotel em que ele estava em Boston, pois havia sido reprovado em matemática, e ao chegar lá, encontra seu pai com uma mulher no quarto. $\mathrm{O}$ fato de ter constatado o que se tornou um grande erro (a traição) de Willy, levou Biff a desconstruir a imagem de herói que ele tinha do pai. A partir de então, o jovem adentra em um processo inconsciente de destruição do pai (pelo desprezo que passa a lhe conferir) e de si mesmo (abandonando todos os sonhos que tinha para um futuro de conquistas e glórias - uma forma de punir Willy).

A respeito da peripécia, Aristóteles afirma ser "uma reviravolta das ações em sentido contrário, como ficou dito; e isso, repetimos, segundo a verossimilhança ou necessidade [...]" (ARISTÓTELES, 1985, p. 30). A peripécia situa-se no momento em que o destino do herói tem uma virada inesperada, passando da felicidade para a infelicidade; isso ocorre de modo verossímil. Na peça de Miller, o momento em que ocorre a peripécia é quando Willy, após se humilhar diante do seu patrão Howard e ser demitido da empresa, vai ao encontro de seus filhos em um bar, na esperança de que Biff tivesse conseguido o emprego com um antigo conhecido da família, Oliver, mas descobre que tudo deu errado:

WILLY: I've been waiting for you to explain since I sat down here! What happened? He took you into his office and what? (p. 108)

BIFF: Well - I talked. And - and he listened, see. (p. 108)

WILLY: You didn't see him, did you? (p. 109)

BIFF: I did see him! (p. 109)

HAPPY: What the hell! (p. 109)

WILLY: Tell me what happened! (p. 109)

BIFF, to HAPPY: I can't talk to him! (MILLER, 1972, p. 108 e 109). ${ }^{4}$

Após ser demitido, Willy tem a ilusão de oportunidade na conversa de Biff com Oliver, porém o homem não reconheceu Biff, e quando este estava saindo, roubou-lhe uma caneta do escritório (um antigo hábito, despretensiosamente encorajado por Willy), e agora receava devolvê-la e assumir-se culpado. Dessa maneira, Willy reconhece a real situação e começa a ter lembranças do passado, a ouvir vozes; fatos que o deixam profundamente atormentado com o tempo presente, visto não ter mais a perspectiva de que o filho realizaria o

\footnotetext{
${ }^{2}$ WILLY: Eu estou esperando que você me explique desde que me sentei aqui! O que aconteceu? Ele levou você ao escritório dele e o que?

Biff: Bem - eu falei. E - e ele ouviu, veja.

WILLY: Você não o viu, não é?

Biff: Eu o vi!

FELIZ: Que diabo!

WILLY: Diga-me o que aconteceu!

Biff, a feliz: Eu não posso falar com ele! (MILLER, 1949, p. 108 e 109, tradução nossa).
} 
Sonho Americano de sucesso material por si mesmo - Willy opta pelo suicido para que o seu seguro de vida garanta uma fonte de renda e dê oportunidade para Biff.

O segundo elemento tratado por Aristóteles são os caracteres (os personagens), sobre os quais, em sua Poética, o autor define quatro características a serem apresentadas por eles. Os personagens devem ser bons, possuir caráter; adequados, ter comportamento adequado; semelhantes, dotados de verossimilhança (o possível e plausível); e constantes, coerentes e consistentes, mantendo o mesmo comportamento do início ao fim. Dessa maneira, é possível notar que Death of a salesman (1972) segue esses princípios relacionados aos personagens, visto que, primeiro, Willy é basicamente um homem bom e com boas intenções, prezando pela felicidade de sua família; segundo, seu comportamento, suas falhas e erros estão sempre ligados à boa intenção de ser o provedor da família; além disso, é um personagem verossímil e consistente, uma vez que ele mantém o mesmo comportamento durante a peça e seus atos são previsíveis do começo ao fim.

Em relação ao herói trágico, Aristóteles diz que ele deve ser superior e bom, o qual está destinado a cometer uma falha trágica (hamartia) $)^{5}$ que o leva a um erro de julgamento, desencadeando toda a tragédia outrora destinada pelos deuses, não podendo o herói salvar-se de sua destruição. Diferentemente, a tragédia moderna representa a figura do herói trágico por meio do homem comum e imperfeito, o qual possui falhas e fraquezas que irão levá-lo a cometer a falha trágica, causadora da tragédia que pode ser evitável. Em Death of a salesman (1972) o herói trágico é representado por Willy Loman, o qual é um homem comum, repleto de falhas e fraquezas, que deseja ser bom e adere ao que é bom como objetivo de vida, mas termina sendo corrompido pelas escolhas erradas que vão além do seu controle, as quais são determinadas pelos ideais individualistas e materialistas da sociedade americana, repleta de valores e crenças relacionados à busca exacerbada pelo sucesso financeiro.

Aristóteles trata do terceiro elemento da tragédia, ideias, o qual o autor define como a faculdade de dizer o que é possível e pertinente em determinadas circunstâncias. O pensamento está relacionado à expressão, de modo que a expressão verbal deve coincidir com os pensamentos do personagem. Em relação ao quarto elemento, Aristóteles diz ser $a$ produção de efeitos visuais, os quais são enfatizados na encenação de sua peça, visando produzir efeitos emocionais no público, como é perceptível através do jogo de luzes e efeitos em Death of a salesman. Por fim, Aristóteles caracteriza o som como sendo o último elemento constituinte da tragédia, o qual introduz a atmosfera da peça. No texto de Miller, o

\footnotetext{
${ }^{5}$ Erro involuntário na construção da ação trágica que desencadeia a peripetéia (ARISTÓTELES, 1985).
} 
som da flauta é um importante recurso que determina a atmosfera de sonho e fantasia presentes no enredo.

\section{Conclusão}

É possível observar que Death of a salesman (1972) além de ser uma obra importante no cenário americano, uma vez que discute a temática do Sonho Americano, desmistificando a ideia de que os Estados Unidos é o país da riqueza, prosperidade e oportunidade, é também de fundamental importância no cenário mundial, com a temática do conflito entre o indivíduo e a sociedade e da constante busca por inserir-se em um sistema de valores econômicos e sociais.

A partir das análises feitas em relação aos elementos da tragédia presentes no drama moderno de Arthur Miller, é importante notar que o autor não seguiu todas as características postuladas por Aristóteles, no entanto, muitos dos elementos descritos na Poética, os quais são considerados como que essenciais na composição de uma tragédia estão presentes na obra de Miller. Sendo assim, diante dos elementos utilizados na peça para intensificar o conflito familiar de Willy Loman e criar uma atmosfera de ações trágicas, é possível concluir que a obra de Miller é um drama moderno.

\section{Referências}

ARISTÓTELES. A poética clássica. Tradução de Jaime Bruna. São Paulo: Cultrix, 1985.

BALDICK, Chris. Oxford concise dictionary of literary terms. Oxford: Oxford University Press, 1996.

BLOOM, Harold. Arthur Miller: modern critical views. New York: Chelsea House Publishers, 1987.

BIGSBY, C. W. E. Modern American Drama [1945 - 2000]. United Kingdom: Cambridge University Press, 2000.

LUNA, Sandra. Arqueologia da ação trágica: o legado grego. João Pessoa: Idéia, 2005.

MILLER, Arthur. Death of a salesman. New York: The Viking Press, 1972.

PALLOTTINI, Renata. Introdução à dramaturgia. São Paulo: Ática, 1988.

PAVIS, Patrice. Dicionário de teatro. 2 ed. Trad. J. Guinsburg e Maria Lúcia Pereira. São

I Paulo: Perspectiva, 1999.

SZONDI, Peter. Teoria do drama moderno [1880 - 1950]. Tradução de Luiz Sérgio Repa. São Paulo, Cosac \& Naify, 2001. 
WILLIAMS, Raymond. Tragédia Moderna. Tradução de Betina Bischof. São Paulo: Cosac \& Naify, 2002.

Recebido em 01 de janeiro de 2014 Aceito para publicação em 05 de agosto de 2014 